\title{
PERANCANGAN DAN IMPLEMENTASI SERVER UNTUK SISTEM KOMPUTASI AWAN DI INTRANET KAMPUS
}

\author{
Oktaviani \\ 185100029, Sistem Informasi \\ Fakultas Komputer \\ oktaviani.students@umitra.ac.id
}

\begin{abstract}
Pada penggunaan internet yang begitu pesat sekarang membuat internet menjadi begitu dibutuhkan oleh sebagian besar orang. Internet tidak lagi digunakan untuk sekedar mencari berita maupun sebagai bisnis, namun juga digunakan sebagai media komunikasi dengan pengguna lain seperti situs-situs jaringan social contohnya Instagram, Path dan Twitter. Namun penggunaan internet seperti itu masih kurang optimal karena internet juga dapat digunakan untuk menyimpan data pribadi yang dengan mudah dapat diakses kapanpun kita mau atau kita butuhkan dalam bentuk diskless society.
\end{abstract}

Konsep ini yang mendasari munculnya teknologi komputasi awan atau yang lebih dikenal dengan istilah Cloud. Dengan adanya tekonologi ini maka kita sebagai pengguna dapat bergerak bebas dengan data pribadi yang dapat diakses kapan saja dan dimana saja. Tujuan ini guna mengimplementasikan server komputasi awan di intranet kampus dengan tujuan kemudahan perancangan server, implementasi dan mengukur performansi server tersebut agar bisa di dapat karakteristik system ini.

Pada aplikasi Cloud layanan word processing yang dirasa paling dibutuhkan oleh sebagian besar mahasiswa dibandingkan dengan aplikasi lainnya. Mahasiswa dapat mengakses word processing pada server melalui web browser secara intranet. Mahasiswa tidak perlu melakukan instalasi apapun pada device atau pc. Dengan adanya word processing pada server, mahasiswa dapat membuat dokumen, mengubah atau menguploud dokumen dan akan tersimpan dalam storage server.

Kata Kunci : Server, Cloud computing, Intranet, Word Processing 


\section{A. PENDAhuluan}

Materi Kuliah Section 01

Membahas Tentang File Server sampai pada saat ini penggunaan internet masih begitu pesat. Imternet tidak lagi digunakan untuk sekedar mencari berita maupun sebagai bisnis, namun digunakan juga sebagai media komunikasi seperti Intagram, dll. Namun, penggunaan internet tersebut kurang dioptimalkan oleh pengguna karena melalui internet juga dapat digunakan oleh pengguna untuk menyimpan data pribadi yang dengan mudah diakses kapan saja oleh pengguna.

Server adalah komponen penting terlahirnya system Cloud Computing yang dapat meminimalisirkan spesifikasi system pada device ataupun pc.

Dengan adanya teknologi ini maka pengguna dapat bergerak bebas dengan adanya data yang dapat diakses kapan saja dan dimana saja. Segala komputasi terjadi di awan (jaringan internet) dan menjadi infrastruktur public. Teknologi komputasi awan ini juga tidak memerlukan berbagai software, mulai dari Sistem Operasi dan berbagai software lain dalam device pengguna. Device/Pc yang digunakan pun tidak perlu memiliki spesifikasi bagus seperti memori maupun media penyimpanan atau Harddisk yang besar serta processor yang berkecepatan tinggi.

Pada device maupun pc yang digunakan oleh mahasiswa hanya memerlukan suatu web browser ( misalnya, Internet explorer, Opera, Mozilla, Chrome, dll ) dengan suatu koneksi akses ke jaringan internet untuk dapat menggunakan teknologi ini.

\section{B. PEMBAHASAN / STUDI KASUS Perancangan Sistem Server Cloud}

Perancangan server komputasi awan menyediakan layanan teknologi informasi melalui internet, dengan sumber daya virtual seperti harddisk, software dll. Secara umum, dari segi pengguna, komputasi awan tidak memiliki infrastruktur fisik. Sebagian besar infrastruktur komputasi awan terdiri dari layanan yang dkirimkan melalui pusat data dan dibangun pada suatu server. Sebuah contoh sederhana komputasi awan adalah email Yahoo atau Gmail, dll. Pengguna atau client tidak membutuhkan software maupun server untuk menggunakannya. Semua mahasiswa hanya perlu koneksi internet dan mahasiswa dapat melakukan pengiriman email. Server dan manajemen perangkat lunak emailini semua terdapat di atas awan (internet) dan sepenuhnya dikelola oleh penyedia layanan email tersebut seperti Yahoo, Google, dll.

\section{ID SECURITY}

QWTD4452377-ASP-5244166

\section{KESIMPULAN}

Kesimpulan dari materi ini adalah :1. Server yang dikembang pada system komputasi awan ini telah dibuat dan merupakan suatu web server yang menyediakan layanan aplikasi text editor.

\section{E. DISKUSI}

Saya bersama teman saya
bernama Maulidun r Nur
mendiskusikan dengan baik
mengenai Server yang berbentuk
pada aplikasi Cloud untuk
memudahkan mahasiswa dan
kampus mengakses data pribadi yang
dapat disimpulkan sebagai berikut:




\section{Section 01}

1. Cloud computating ialah aplikasi yang dapat memudahkan kampus atau mahasiswa dalam mengakses data pribadi dimana pun berada.

2. Aplikasi Cloud ini pun mempermudah mahasiswa maupun kampus karena aplikasi ini tidak memerlukan device maupun pc dengan spesifikasi tinggi karena aplikasi ini dapat diakses melalui Chrome, Mozilla, Internet explorer.

\section{F. REFERENCE}

[1] O. M. Febriani and A. S. Putra, "Sistem Informasi Monitoring Inventori Barang Pada Balai Riset Standardisasi Industri Bandar Lampung," J. Inform., vol. 13, no. 1, pp. 90-98, 2014.

[2] A. S. Putra, "Paperplain: Execution Fundamental Create Application With Borland Delphi 7.0 University Of Mitra Indonesia," 2018.

[3] A. S. Putra, "2018 Artikel Struktur Data, Audit Dan Jaringan Komputer," 2018.

[4] A. S. Putra, "ALIAS MANAGER USED IN DATABASE DESKTOP STUDI CASE DB DEMOS."

[5] A. S. Putra, "COMPREHENSIVE SET OF PROFESSIONAL FOR DISTRIBUTE COMPUTING."

[6] A. S. Putra, "DATA ORIENTED RECOGNITION IN BORLAND DELPHI 7.0."

[7] A. S. Putra, "EMBARCADERO DELPHI XE 2 IN GPU-POWERED FIREMONKEY APPLICATION."

[8] A. S. Putra, "HAK ATAS KEKAYAAN INTELEKTUAL DALAM DUNIA TEKNOLOGY BERBASIS REVOLUSI INDUSTRI 4.0."

[9] A. S. Putra, "IMPLEMENTASI PERATURAN PERUNDANGAN UU. NO 31 TAHUN 2000 TENTANG DESAIN INDUSTRI BERBASIS INFORMATION TECHNOLOGY."
[10] A. S. Putra, "IMPLEMENTATION OF PARADOX DBASE."

[11] A. S. Putra, "IMPLEMENTATION OF TRADE SECRET CASE STUDY SAMSUNG MOBILE PHONE."

[12] A. S. Putra, "IMPLEMENTATION PATENT FOR APPLICATION WEB BASED CASE STUDI WWW. PUBLIKLAMPUNG. COM."

[13] A. S. Putra, "IMPLEMENTATION SYSTEM FIRST TO INVENT IN DIGITALLY INDUSTRY."

[14] A. S. Putra, "MANUAL REPORT \& INTEGRATED DEVELOPMENT ENVIRONMENT BORLAND DELPHI 7.0."

[15] A. S. Putra, "PATENT AS RELEVAN SUPPORT RESEARCH."

[16] A. S. Putra, "PATENT FOR RESEARCH STUDY CASE OF APPLE. Inc."

[17] A. S. Putra, "PATENT PROTECTION FOR APPLICATION INVENT."

[18] A. S. Putra, "QUICK REPORT IN PROPERTY PROGRAMMING."

[19] A. S. Putra, "REVIEW CIRCUIT LAYOUT COMPONENT REQUIREMENT ON ASUS NOTEBOOK."

[20] A. S. Putra, "REVIEW TRADEMARK PATENT FOR INDUSTRIAL TECHNOLOGY BASED 4.0."

[21] A. S. Putra, "TOOLBAR COMPONENT PALLETTE IN OBJECT ORIENTED PROGRAMMING."

[22] A. S. Putra, "WORKING DIRECTORY SET FOR PARADOX 7."

[23] A. S. Putra, "ZQUERY CONNECTION IMPLEMENTED PROGRAMMING STUDI CASE PT. BANK BCA Tbk."

[24] A. S. Putra, D. R. Aryanti, andBI. 


\section{Section 01}

Hartati, "Metode SAW (Simple Additive Weighting) sebagai Sistem Pendukung

Keputusan Guru Berprestasi (Studi Kasus:

SMK Global Surya)," in Prosiding Seminar

Nasional Darmajaya, 2018, vol. 1, no. 1, pp. 85-97.

[25] A. S. Putra and O. M. Febriani, "Knowledge Management Online Application in PDAM Lampung Province," in Prosiding

International conference on Information Technology and Business (ICITB), 2018, pp. 181-187.

[26] A. S. Putra, O. M. Febriani, and B. Bachry, "Implementasi Genetic Fuzzy System Untuk Mengidentifikasi Hasil Curian Kendaraan Bermotor Di Polda Lampung," SIMADA (Jurnal Sist. Inf. dan Manaj. Basis Data), vol. 1, no. 1, pp. 21-30, 2018.

[27] A. S. Putra, H. Sukri, and K. Zuhri, "Sistem Monitoring Realtime Jaringan Irigasi Desa (JIDES) Dengan Konsep Jaringan Sensor Nirkabel," IJEIS (Indonesian J. Electron. Instrum. Syst., vol. 8, no. 2, pp. 221-232.

[28] D. P. Sari, O. M. Febriani, and A. S. Putra, "Perancangan Sistem Informasi SDM Berprestasi pada SD Global Surya," in Prosiding Seminar Nasional Darmajaya, 2018, vol. 1, no. 1, pp. 289-294. 